\title{
Electropolymerized films of 3-methoxythiophene with a potential sweep-induced gold-like luster
}

\author{
Takuya Tokuda and Katsuyoshi Hoshino
}

Novel electropolymerized films that naturally appeared gold-like and possessed lustrous green color tones were prepared by the cyclic potential-sweep electropolymerization of 3-methoxythiophene. The polymerized products were characterized by different instrumentation techniques, which identified them as oligo(3-methoxythiophene) containing perchlorate and dodecyl sulfate anions. The optical and structural analyses demonstrated that the films consisted of edge-on and face-on lamellar structures of the oligomers, and that the edge-on structures contributed to the development of the gold-like luster. The role of the cyclic potential sweep was interpreted as the preferential destruction of the face-on lamellar structures and a contribution to the increasing effects of the edge-on lamellar structures.

Polymer Journal (2016) 48, 1141-1149; doi:10.1038/pj.2016.86; published online 5 October 2016

\section{INTRODUCTION}

Recently, significant efforts have been made to produce metal-like lustrous colors (gold, silver and bronze) without using metals. The first attempts to intentionally synthesize low-molecular-weight organic compounds with a metal-like luster were undertaken by Ogura et al. ${ }^{1-6}$ These studies were followed by the discovery of some low-molecular-weight ${ }^{7,8}$ compounds and polymer compounds ${ }^{9-11}$ with good metal-like lusters. We also developed an organic oligomeric compound, which was the first that could be dissolved in organic solvents to provide coating solutions. ${ }^{12}$ The coating solutions were applied to glass and polyester plates to produce gold-like lustrous films that were stable under ambient conditions for at least one year. In the background of such studies lies the fact that the metal-like luster contributes not only to the design of coatings but also to the engineering applications in areas such as energy conservation and forgery prevention. The application of the luster in cars and buildings prevents the buildup of heat by reflecting incoming solar radiation and reduces the use of air-conditioning for cooling. ${ }^{13}$ Lustrous prints cannot be easily copied using reprographic techniques, thus making forgery much more difficult to carry out. ${ }^{14}$

Except for one polymer film, the lustrous compounds developed were chemically prepared. This unique polymer film ${ }^{11}$ was prepared by the electropolymerization of bithiophene in a cholesteric liquid crystal, and it exhibited a potential-dependent appearance of a metallic reflection color, that is, bronze, silver and gold, on irradiation with white light at oblique angles (the polymer intrinsically appeared red and blue in color depending on the applied potential). The electropolymerization method has some advantages over the chemical method: (1) most of the electropolymerization products are obtained in the form of films; (2) the film thickness can be controlled by varying the amount of electricity; (3) films with a uniform thickness are formed, even on nonplanar substrates, due to the high throwing power specific to electrochemical methods; and (4) the doping level of the films can be controlled by varying the applied potential.

In this study, we report the electrosynthesis of perchlorate-doped oligo(3-methoxythiophene) films and the discovery that the films show an intrinsic gold-like luster. The mechanism of the development of this gold-like luster is also discussed on the basis of the optical and structural properties of the films. In addition, it is reported that the dedoping of the film produces a green lustrous film.

\section{EXPERIMENTAL PROCEDURE}

Materials and electrolysis system

3-Methoxythiophene (Sigma-Aldrich, Tokyo, Japan, >98\%), $\mathrm{LiClO}_{4}$ (Wako Pure Chemical Industries, Osaka, Japan, >98\%), sodium dodecyl sulfate (abbreviated as SDS, Wako Pure Chemical Industries), 1-butanol (Kanto Chemical, Tokyo, Japan, >99\%) and water (Wako Pure Chemical Industries, for HPLC) were used as supplied. The oligo(3-methoxythiophene) films were prepared on an indium tin-oxide (ITO)-coated glass plate (Geomatec, Tokyo, Japan, $10 \Omega \mathrm{sq}^{-1}$ ) by the cyclic potential-sweep electropolymerization of 3methoxythiophene under a $\mathrm{N}_{2}$ atmosphere using a potentiostat (BAS, Tokyo, Japan, electrochemical analyzer model ALS 600DH). The electrolyte solution, which was developed by Fall et al. ${ }^{15-18}$ was prepared by dissolving $0.1 \mathrm{M} \mathrm{3-}$ methoxythiophene, $0.1 \mathrm{M}$ SDS and $0.1 \mathrm{M} \mathrm{LiClO}_{4}$ in a mixed solvent of water/1butanol (96:4 vol. ratio). The working ITO electrode and the counter Pt plate were immersed in the main compartment of the electrolysis cell (Supplementary Figure S1). The auxiliary compartment, which was separated from the main one by a sintered glass frit, had an immersed $\mathrm{KCl}$ agar bridge connected to the reference saturated calomel electrode.

\section{Oligomer characterization}

The FT-IR transmission spectra of the oligomers ( $\mathrm{KBr}$ pellets) were recorded using a Jasco FT/IR-410 spectrometer (Jasco, Tokyo, Japan). The ${ }^{1} \mathrm{H}$ NMR 
spectra were recorded in a DMSO- $d_{6}$ solution by a Varian NMR system (Varian, Palo Alto, CA, USA). All the chemical shifts ( $\delta$ in p.p.m.) were referenced to tetramethylsilane. Gel permeation chromatography (GPC) measurements were conducted using a Jasco RI-2031 Plus (Jasco) equipped with a Hitachi UV-4200 (Hitachi, Tokyo, Japan) and two Shodex KF-806M columns (Showa Denko, Tokyo, Japan). NMP (1-methyl-2-pyrrolidone) containing $0.01 \mathrm{~m}$ lithium bromide was used as the eluent (elution rate, $0.4 \mathrm{ml} \mathrm{min}^{-1}$ ), and polystyrene standards were used for calibration.

\section{Film characterization}

The UV-Vis reflection spectra were obtained using a JASCO MSV-370 spectrometer, in which the incident and reflection angles were $22^{\circ}$ from the vertical position. The spectra were recorded at room temperature using an evaporated aluminum film as the reference material. Gold $(0.20-\mu \mathrm{m}$ thick $)$ and copper films $(0.22-\mu \mathrm{m}$ thick) were deposited on a glass plate by a vacuum evaporation method. The observation of the films was made using an optical microscope (VHX-5000, KEYENCE, Osaka, Japan). The arithmetic average roughness $\left(R_{\mathrm{a}}\right)$ was determined by using a laser microscope (VK-9700, KEYENCE). Energy-dispersive X-ray analysis (EDX, JEOL JED-2300/2300F Analysis Station, Tokyo, Japan) was employed for the compositional analyses of the sample films. X-ray diffraction (XRD) measurements were performed using a diffractometer (Rigaku Smart Lab, Tokyo, Japan) equipped with a Cu-Ko source in the $2 \theta$ scanning mode at a fixed incident angle of $1^{\circ}$.

Film thicknesses were measured using a surface profile measuring system (Sloan, model Dektak 3030, now Veeco, Plainview, NY, USA). A solution of polycarbonate $\left(\mathrm{PC}\right.$, Teijin, Osaka, Japan, average molecular weight $\left.=6.5 \times 10^{4}\right)$, prepared by mixing PC and chloroform (Kanto Chemical, $>99 \%$ ) in a weight ratio of 1:6, was applied to the sample films deposited on the ITO, and freestanding films with the sample films attached on one side of the surface were obtained by peeling the layered films from the ITO. The electric conductivity of the sample films, $\sigma$, was measured by a four-point-probe method using a Loresta-GP (MCP-T610, Mitsubishi Chemical Analytech, Chigasaki, Japan) instrument.

\section{RESULTS AND DISCUSSION}

\section{Preparation of metal-like lustrous films by the potential-sweep} method

The linear sweep voltammetry of 3-methoxythiophene was carried out using the electrolysis system (described above), in which the ITO electrode was immersed in the electrolyte solution developed by Fall et al. ${ }^{16}$ (Figure 1a). The oxidation current due to the polymerization of 3-methoxythiophene flowed for potential values above $\sim 1 \mathrm{~V}$, and film deposition occurred on the ITO. On the basis of this voltammogram, as is usual with electropolymerization, the controlled-potential electrooxidation of 3-methoxythiophene was performed at 1.1, 1.2, 1.3, 1.4 and $1.5 \mathrm{~V}$ (where the amount of electricity, $Q=0.40 \mathrm{C} \mathrm{cm}^{-2}$ ), however, less lustrous purple films with a thickness of $1.8 \mu \mathrm{m}$ were only obtained.

Next, the electropolymerization was carried out using multisweep cyclic voltammetry. Figure $1 \mathrm{~b}$ shows the cyclic voltammograms measured in the potential range of -0.5 to $1.3 \mathrm{~V}$ at a sweep rate of $10 \mathrm{mV} \mathrm{s}^{-1}$ (with a starting potential of $0 \mathrm{~V}$ ). As the potential was

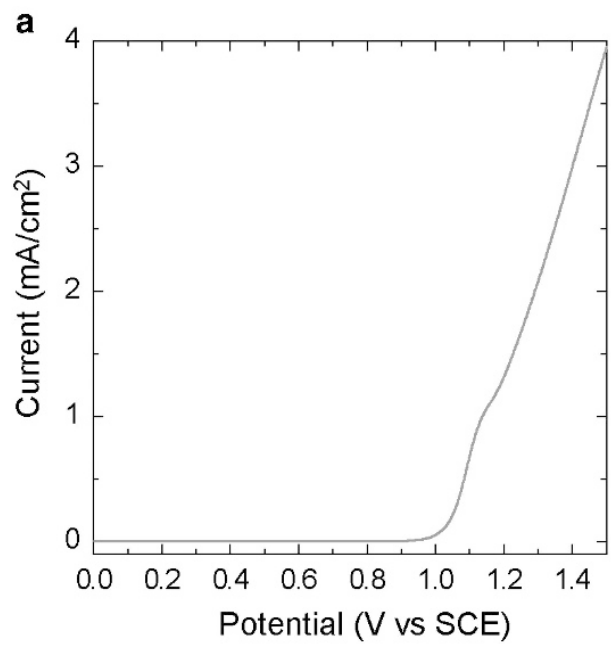

b

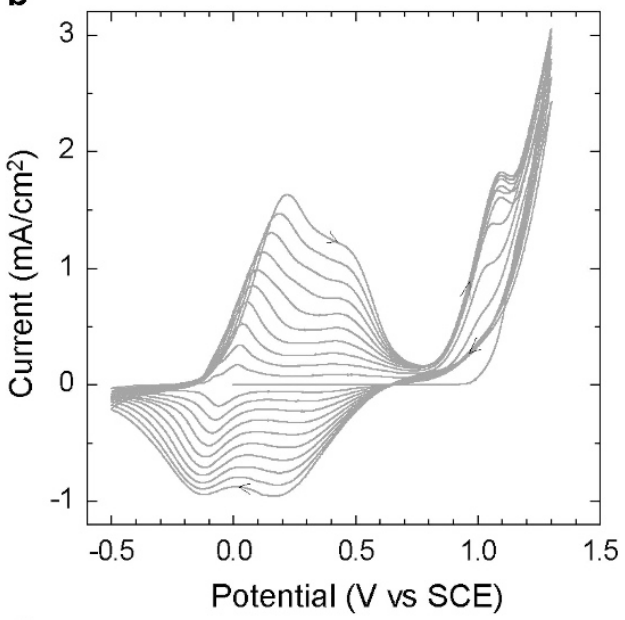

C

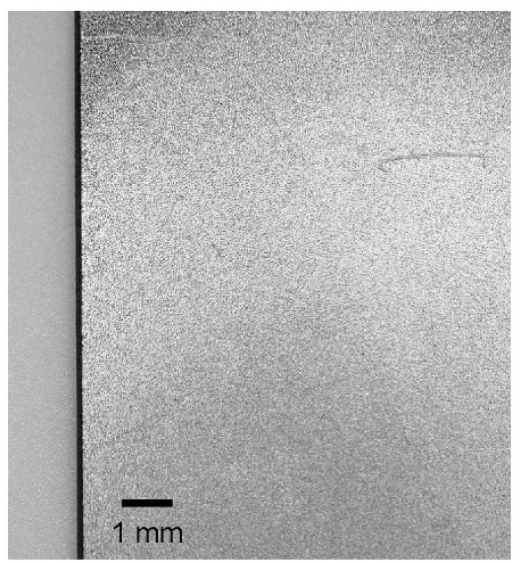

d

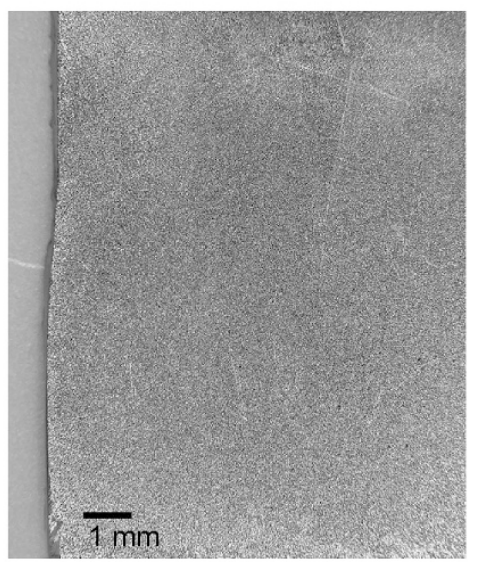

Figure 1 Linear sweep (a) and cyclic voltammograms (b) of $0.1 \mathrm{~m}$ 3-methoxythiophene at an ITO electrode in a mixed solvent of water/1-butanol (96:4 vol. ratio) containing $0.1 \mathrm{~m}$ sodium dodecyl sulfate (SDS) and $0.1 \mathrm{~m} \mathrm{LiClO}$. Sweep rate: $10 \mathrm{mV} \mathrm{s}^{-1}$. (c, d) The digital microscope images of gold-like and green lustrous films obtained by the cyclic potential-sweep electropolymerization of 3-methoxythiophene. A full color version of this figure is available at Polymer Journal online. 
swept repeatedly, the anodic currents (for potentials of -0.2 to $0.8 \mathrm{~V}$ ) and cathodic currents (for potentials of 0.7 to $-0.5 \mathrm{~V}$ ) increased. The anodic currents are attributed to the oxidation or doping of anions (the formation of polarons and bipolarons), and the cathodic currents are due to the reduction or dedoping of the anions. The anions are $\mathrm{ClO}_{4}{ }^{-}$ and dodecyl sulfate $\left(\mathrm{DS}^{-}\right){ }^{15-18}$ The $\mathrm{DS}^{-}$anion is harder to remove from the film due to its hydrophobic nature, and therefore, it was reported that the cathodic currents partially involve the trapping of cations. ${ }^{15}$ An anodic current observed at a potential of $\sim 1 \mathrm{~V}$ initially increased as the potential sweep increased and then became constant. This may be reasonably explained by assuming that the electro-oligomerization potential at the generated oligomer film on the ITO is lower than that at the bare ITO plate, and the real surface area of the oligomer film initially increased, then reached a steady-state value. Up to the seventh potential sweep, the film exhibited electrochromism between blue (oxidized state) and red (reduced state), but it did not show this property when the sweep was repeated further because the film was intensely colored (reddish purple) when observed visually. After the completion of the eleventh potential sweep, the electrolysis was stopped at $1.3 \mathrm{~V}$ and the film attached to the ITO (abbreviated as film $\mathrm{ox}_{\mathrm{X}}$ ) was removed from the electrolyte; the resulting film was a gold-like lustrous film with a thickness of $2 \mu \mathrm{m}$ and an arithmetic average roughness $\left(R_{\mathrm{a}}\right)$ of 0.83 (Figure 1c). The film was then carefully washed in the mixed solvent of water/1butanol (96:4 vol. ratio) and dried in air. When the electrolysis was stopped at $-0.5 \mathrm{~V}$ after the completion of the tenth potential sweep, a green film with a metal-like luster (film ${ }_{\text {red, }}, 1.8-\mu \mathrm{m}$ thick, $R_{\mathrm{a}}=0.96$ ) was obtained, as shown in Figure 1d. As observed from the digital microscopic images and the $R_{\mathrm{a}}$ values, surfaces for film $\mathrm{ox}$ and film $\mathrm{red}_{\mathrm{red}}$ have a fine roughness; their $R_{\mathrm{a}}$ values are much higher than that of the ITO plate $\left(R_{\mathrm{a}}=0.015\right)$.

\section{Characterization of metal-like lustrous films}

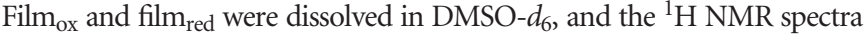
were recorded. Similar to previous reports, ${ }^{12,19}$ the spectra were recorded after the dissolution state of the oligomer reached an equilibrated state (at least 3 days after the solution was prepared). The spectra exhibited signals at 4 and 7.1 p.p.m. (Figures $2 \mathrm{a}$ and $2 \mathrm{~b}$ ), which can be assigned to the three methoxy protons and one aromatic proton at the 4-position of the thiophene ring, respectively, ${ }^{20,21}$ on the basis of the value of the chemical shift and the comparison of the area of the proton peaks. The insets I and III of Figures $2 \mathrm{a}$ and $\mathrm{b}$ show the expanded spectra in the region of chemical shifts of methoxy protons. The peaks at 3.98 p.p.m. and $~ 3.8$ p.p.m. can be assigned to head-to-tail (HT) and head-to-head (HH) configurations, respectively. The intensity ratio of the two peaks suggests that the oligomer mainly consists of HT configurations but contains a small number of $\mathrm{HH}$ configurations. ${ }^{22,23}$ The aromatic protons in the thiophene ring give rise to several signals (see the insets II and IV of Figures $2 \mathrm{a}$ and $\mathrm{b}$ ). According to the previous studies concerning poly(3-alkylthiophene)s, these signals correspond to the four triads (HT-HT, HT-HH, TT-HT and TT-HH triads) and the 4-/5protons on the terminal 2-substituted 3-methoxythiophene rings. ${ }^{22}$ As the main configuration is the HT configuration, as described above, the most intense peak at 7.13 p.p.m. is attributed to the HT-HT triad. The peak at 8.14 p.p.m. was tentatively assigned to the 5-proton on the terminal 4-substituted 3-methoxythiophene ring by the estimation of ${ }^{1} \mathrm{H}$ NMR chemical shifts using a ChemNMR program in a CS ChemBioDraw Ultra version 13.0 (PerkinElmer, Waltham, MA, USA). ${ }^{24,25}$ However, the complete assignment of the aromatic proton signals above should be performed after obtaining the NMR spectra, including the two-dimensional NMR spectra. Studies to characterize the regiochemistry of the oligomers are underway. These NMR results strongly suggest that the oligomer is oligo(3-methoxythiophene). The signals at 2.49 and 3.51 p.p.m. are attributed to the residual DMSO protons and water, respectively. ${ }^{26}$ The signals at $3.70,1.48,1.25$ and 0.86 p.p.m. are ascribed to the protons in $\mathrm{DS}^{-}{ }^{27}$ On the basis of the peak area ratio, the molar ratio of the $\mathrm{DS}^{-}$and thiophene ring unit was 0.30 . On the other hand, the EDX analysis of film $\mathrm{ox}_{\text {p }}$ provided an atomic $\mathrm{Cl} / \mathrm{S}$ ratio of 0.18 . These two results revealed that the doping level of $\mathrm{ClO}_{4}{ }^{-}$was $23 \%$ and the content of $\mathrm{DS}^{-}$in filmox was $30 \%$. Similarly, the doping level of $\mathrm{ClO}_{4}^{-}$

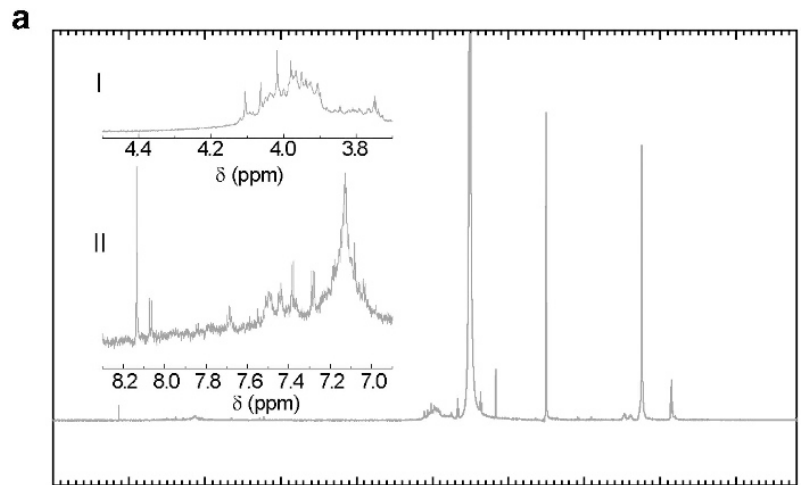

b
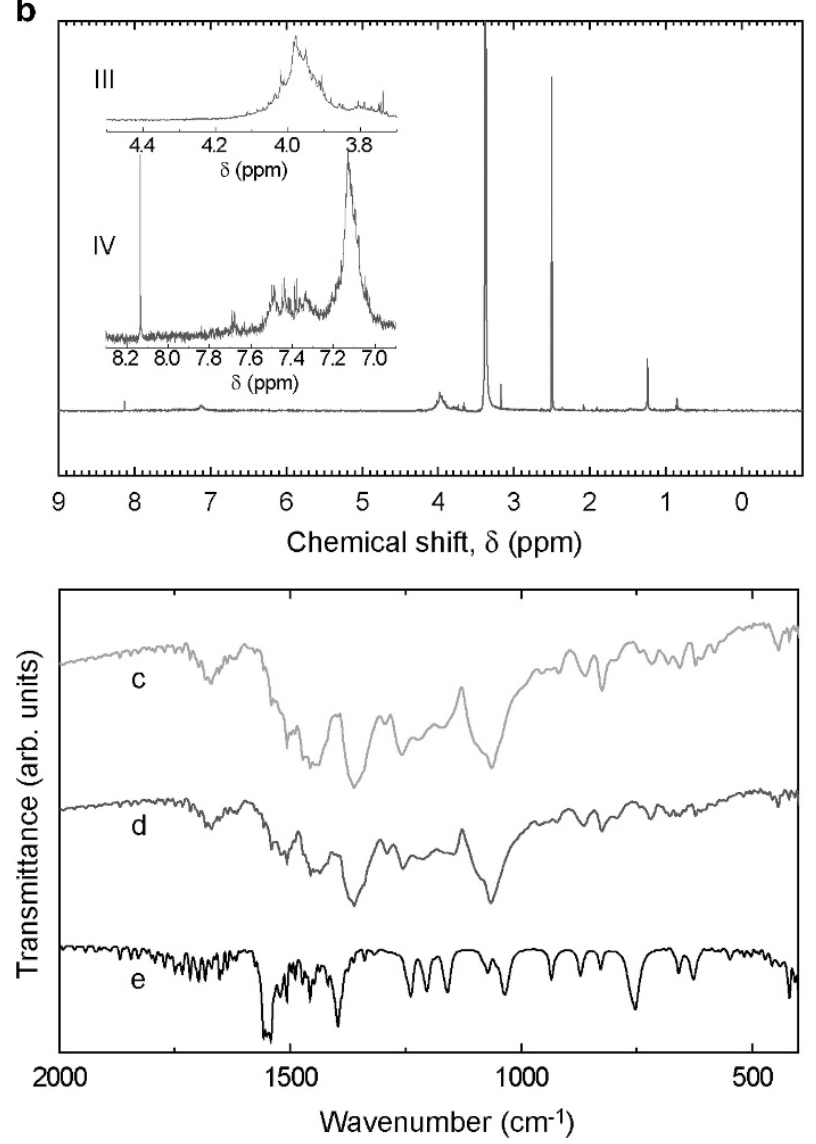

Figure $2{ }^{1} \mathrm{H}$ NMR spectra of the DMSO- $d_{6}$ solutions prepared by dissolving film $_{\text {ox }}$ (a) and film $m_{\text {red }}$ (b). The insets show expanded ${ }^{1} \mathrm{H}$ NMR spectra of methoxy (I and III) and aromatic (II and IV) protons for film $\mathrm{ox}_{\mathrm{O}}(\mathrm{I}$ and II) and film $_{\text {red }}$ (III and IV). Curves $\mathrm{c}, \mathrm{d}$ and e show the FT-IR spectra of $\mathrm{KBr}$ pellets containing filmox film $_{\text {red }}$ and 3-methoxythiophene, respectively. The pellets were prepared by mixing $\mathrm{KBr}$ and the oligomers obtained by scratching the films off the ITO plate. A full color version of this figure is available at Polymer Journal online. 
and the content of $\mathrm{DS}^{-}$in film red were 8.3 and $6 \%$, respectively. Aaron and colleague ${ }^{16}$ immersed a Pt electrode into a similar electrolyte system as the one described above and prepared a dark-brown composite film of poly(3-methoxythiophene)-poly(bithiophene) by sweeping the potential twenty times between -0.4 and $1.3 \mathrm{~V}$ versus saturated calomel electrode. The XPS analyses demonstrated that the oxidized film was doped with $25 \% \mathrm{ClO}_{4}^{-}$and included $61 \% \mathrm{DS}^{-}$with respect to the thiophene unit, and the $\mathrm{ClO}_{4}^{-}$and $\mathrm{DS}^{-}$values were $10 \%$ and $32 \%$, respectively, for the reduced film.

The $c, d$ and e curves in Figure 2 show the FT-IR spectra of film ${ }_{\mathrm{ox}}$, film $\mathrm{m}_{\text {red }}$ and 3-methoxythiophene monomer, respectively. The $\mathrm{C}_{\beta}-\mathrm{H}$ inplane deformation ${ }^{16}$ band at $1065 \mathrm{~cm}^{-1}$ was obtained in all the spectra, however, the peaks for the $\mathrm{C}_{\alpha}-\mathrm{H}$ in-plane bending vibrations ${ }^{21}$ at 1238 and $1158 \mathrm{~cm}^{-1}$, which were visible in curve e, were not observed in curves $\mathrm{c}$ and $\mathrm{d}$. The peak at $820 \mathrm{~cm}^{-1}$ in curves $\mathrm{c}$ and $\mathrm{d}$ is assigned to the $\mathrm{C}-\mathrm{H}$ deformation vibration of the 2,3,5-trisubstituted thiophene ring. ${ }^{28,29}$ The peak at $1258 \mathrm{~cm}^{-1}$ observed in all the spectra is assigned to the $\mathrm{C}-\mathrm{O}-\mathrm{C}$ stretching vibration of the methoxy group. ${ }^{30}$ In addition, the bands at $1360 \mathrm{~cm}^{-1}$ and $\sim 1090 \mathrm{~cm}^{-1}$ (a shoulder) in curves $\mathrm{c}$ and $\mathrm{d}$ are attributed to the antisymmetric stretching mode of $\mathrm{S}=\mathrm{O}$ in the $\mathrm{DS}^{-}$ion ${ }^{31}$ and $\mathrm{ClO}_{4}{ }^{-}$ion, ${ }^{30}$ respectively. These FT-IR measurement results demonstrated that the films were identified as oligo(3-methoxythiophene) containing $\mathrm{ClO}_{4}^{-}$and $\mathrm{DS}^{-}$.

The GPC analyses indicated that the weight-averaged molecular weights, $M_{\mathrm{w}}$ (or number-averaged molecular weight, $M_{\mathrm{n}}$ ), of the oligomers in film ${ }_{\mathrm{ox}}$ and film $\mathrm{m}_{\mathrm{red}}$ were $M_{\mathrm{w}}=2.1 \times 10^{3}$ (or $M_{\mathrm{n}}=1.4 \times 10^{3}$ ) and $M_{\mathrm{w}}=2.0 \times 10^{3}$ (or $\left.M_{\mathrm{n}}=1.4 \times 10^{3}\right)$, respectively, and the value of $M_{\mathrm{w}}$ had a broad distribution extending to $10^{4}$. These values of $M_{\mathrm{w}}$ correspond to 18-19 degrees of oligomerization, which is somewhat lower than that for the oligomer prepared in acetonitrile by chemical oxidation with $\mathrm{Fe}$ $\left(\mathrm{ClO}_{4}\right)_{3}, M_{\mathrm{w}}=2.4 \times 10^{3} .{ }^{12}$ This is probably because the electrogenerated 3-methoxythiophene cation radical is trapped at the water-SDS micelle interface and reacts with water, which suppresses the electrophilic aromatic substitution reaction of the cation radical with a neutral monomer and slows the electro-oligomerization. ${ }^{32}$

Figure 3 shows the reflection spectra of film ${ }_{\text {ox }}$ (a) and film red $_{\text {(b). }}$ For comparison, the film prepared by applying the chemically synthesized oligomer (film ${ }^{\circ}$, curve $c, 1.8-\mu \mathrm{m}$ thick) and the vacuumevaporated gold film on a glass plate (curve e, $0.20-\mu \mathrm{m}$ thick) are also shown. The light reflectance of film ${ }^{\circ}$ in the region (reflectance 1) of yellow $(570-590 \mathrm{~nm})$, orange $(590-620 \mathrm{~nm})$ and red wavelengths $(620-750 \mathrm{~nm})$ is much higher than that in the region (reflectance 2) of purple $(380-450 \mathrm{~nm})$ and blue wavelengths $(450-495 \mathrm{~nm})$ as is the case for the vacuum-evaporated gold film, resulting in the gold-like coloration. Film $\mathrm{ox}$ also showed similar reflection characteristics; however, the value of reflectance 1 is lower than that for film ${ }^{\circ}$, and film $_{\mathrm{ox}}$ has a gold-like luster with a lower lightness level compared with the film ${ }^{\circ}$ and the vacuum-evaporated gold film. Considering that the $R_{\mathrm{a}}$ value of 0.83 of film $_{\mathrm{ox}}$ is much higher than that of film $^{\circ}$ $\left(R_{\mathrm{a}}=0.018\right)$ as described above, the lower lightness level of film $\mathrm{ox}_{\mathrm{x}}$ can be partly attributed to its higher light scattering characteristics. For film $\mathrm{m}_{\text {red }}$, the light reflectance in the region of green wavelengths $(495-570 \mathrm{~nm})$ is high, resulting in the development of the green luster. On the other hand, the reflection spectrum of the controlledpotential electropolymerized film $\left(\right.$ film $_{\mathrm{cp}}$ ) is also shown as curve $\mathrm{d}$ in Figure 3. This $1.8-\mu \mathrm{m}$-thick film was prepared by applying a potential of $1.2 \mathrm{~V}$ at $Q=0.40 \mathrm{C} \mathrm{cm}^{-2}$ in the same electrolyte solution as that employed for the preparation of film $\mathrm{ox}_{\mathrm{o}}$. Compared with the film $\mathrm{ox}$ (curve a), the reflectance in the green region $(495-570 \mathrm{~nm})$ and reflectance 1 decreased, leading to a condition where neither reflection 1 nor reflection 2 is given priority. In addition, the overall reflectance

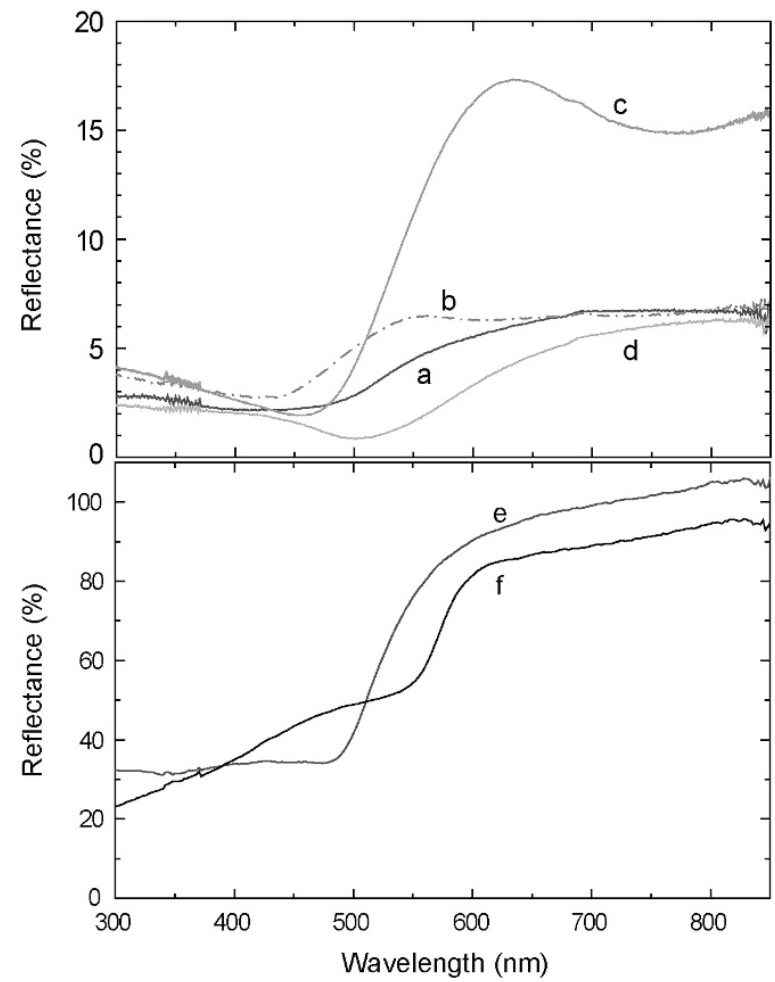

Figure 3 Reflection spectra of filmox (curve a, 2- $\mu \mathrm{m}$ thick), film $\mathrm{m}_{\mathrm{red}}$ (curve $\mathrm{b}$, 1.8 $-\mu \mathrm{m}$ thick), film ${ }^{\circ}$ (curve $\mathrm{c}, 1.8 \mu \mathrm{m}$ thick) and film $\mathrm{cp}_{\mathrm{cp}}$ (curve $\mathrm{d}, 1.8-\mu \mathrm{m}$ thick). Curves $e$ and $f$ show the reflection spectra of the evaporated gold $(0.20-\mu \mathrm{m}$ thick) and copper films $(0.22-\mu \mathrm{m}$ thick), respectively. A full color version of this figure is available at Polymer Journal online.

reduced. For these two reasons, film $\mathrm{cp}_{\mathrm{cp}}$ appeared purple with a lower luster. However, reflectance 1 slightly exceeds reflectance 2, and accordingly, a slight gold-like reflection was observed when the film was viewed from the oblique direction. EDX, ${ }^{1} \mathrm{H}$ NMR (Supplementary Figure S2) and GPC analyses revealed that film $\mathrm{cp}_{\mathrm{cp}}$ consisted of oligomers with $M_{\mathrm{w}}=1.7 \times 10^{3}$ (or $M_{\mathrm{n}}=1.3 \times 10^{3}$ ) containing $23 \% \mathrm{ClO}_{4}{ }^{-}$and $35 \% \mathrm{DS}^{-}$with respect to the thiophene unit. These values do not significantly differ from those of the oligomers in film $_{\mathrm{ox}}$, therefore, it is reasonable to assume that the difference in the color tone and lustrous properties between film $\mathrm{ox}_{\mathrm{x}}$ and film $_{\mathrm{cp}}$ is not caused by the difference in the molecular structures of the oligomers.

\section{Mechanistic consideration of gold-like luster [I]}

The optical properties of film $\mathrm{ox}_{\mathrm{ox}}$, film $\mathrm{red}_{\mathrm{red}}$ and film $\mathrm{m}_{\mathrm{cp}}$ were investigated to determine the cause of the development of their luster. The optical properties of the solids are described in terms of the complex index of refraction $N=n+\mathrm{i} k$, where $n$ and $k$ are the refractive index and the extinction coefficient, respectively. To calculate the values of $n$ and $k$ at different wavelengths, $\lambda$, the following relationships are used: ${ }^{33,34}$

$$
\begin{aligned}
& n=\frac{1+R}{1-R}+\sqrt{\frac{4 R}{(1-R)^{2}}-k^{2},} \\
& \alpha=\frac{1}{d} \ln \left\{\frac{(1-R)^{2}}{2 T}+\sqrt{\frac{(1-R)^{4}}{4 T^{2}}+R^{2}}\right\}, \\
& k=\frac{\alpha \lambda}{4 \pi},
\end{aligned}
$$




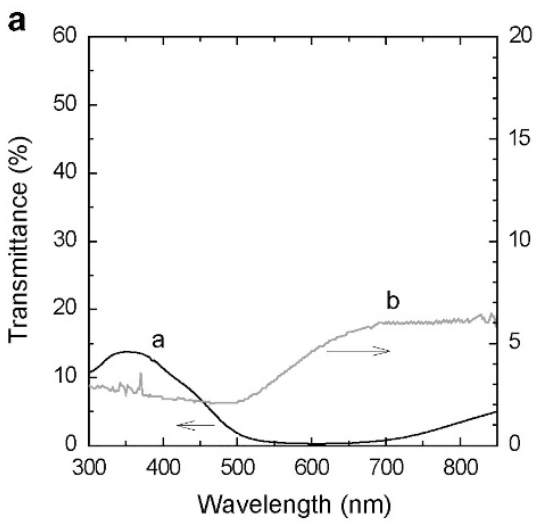

b
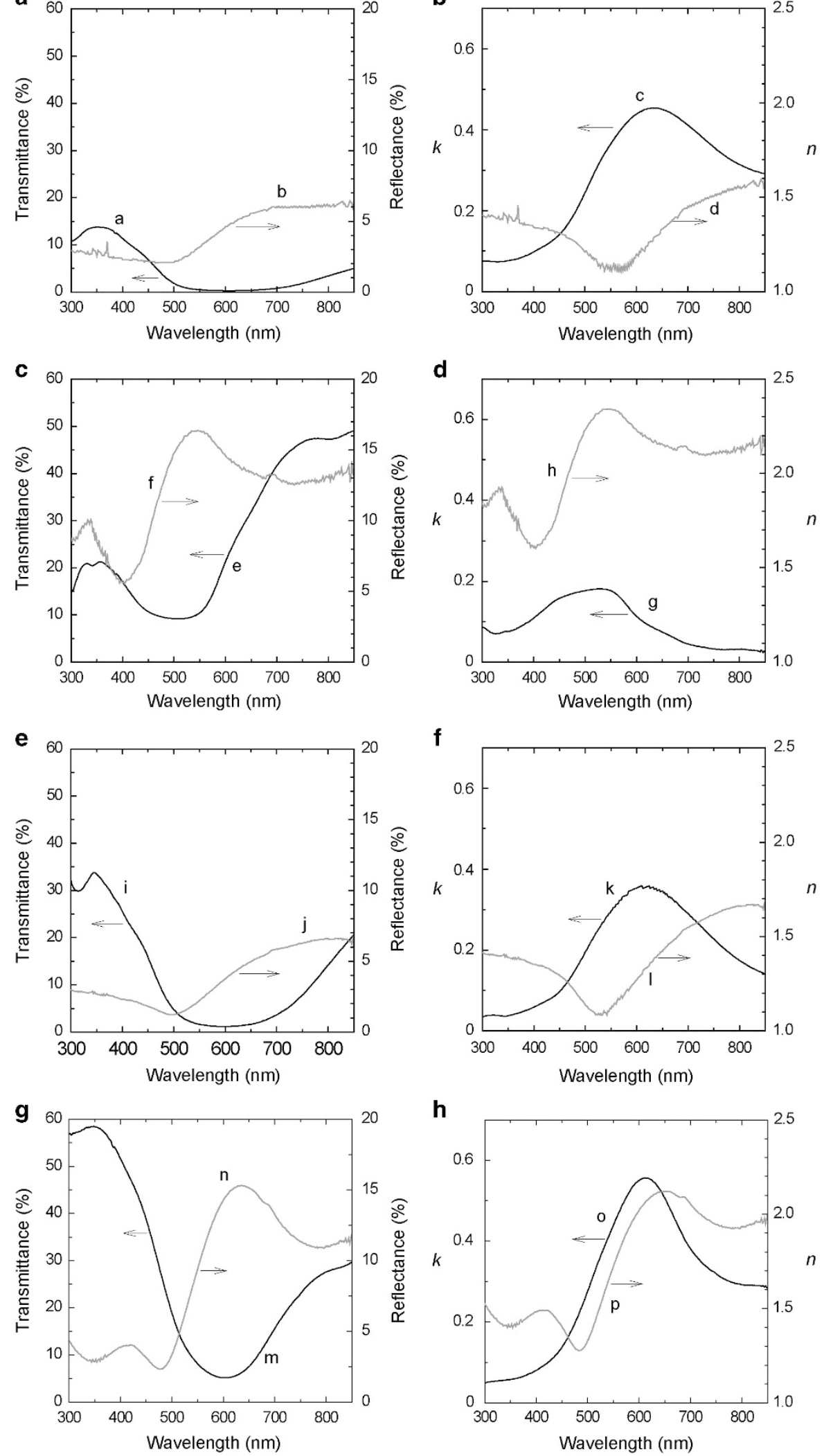

Figure 4 Transmission (curves a, e, i and $m$ ) and reflection spectra (curves $b, f, j$ and $n$ ) for filmox (curves a and $b$ in part a, $0.60-\mu m$ thick), film $m_{\text {red }}($ curves e and $f$ in part $c, 0.43-\mu m$ thick), film $m_{c p}$ (curves $i$ and $j$ in part $e, 0.56-\mu m$ thick) and film (curves $m$ and $n$ in part $g, 0.23-\mu m$ thick). The values of the reflective index $n$ (curves $d, h, I$ and $p$ ) and extinction coefficient $k$ (curves $c, g, k$ and o) for filmox (curves $c$ and $d$ in part b), film red (curves $g$ and $h$ in part d), fil $m_{c p}$ (curves $k$ and $I$ in part $\mathbf{f}$ ) and film (curves 0 and $p$ in part $\mathbf{h}$ ) were calculated from the transmission and reflection spectra. A full color version of this figure is available at Polymer Journal online. 
where $\alpha$ and $d$ are the absorption coefficient and film thickness, respectively, and $R$ and $T$ are the reflectance and transmittance when the light enters the film surface vertically, respectively. By transforming equation (1) for $R$, one obtains the following:

$$
R=\frac{(n-1)^{2}+k^{2}}{(n+1)^{2}+k^{2}}
$$

In our measurements of $R$, the incident angle of the light beam is $22^{\circ}$ perpendicular to the film surface, therefore, equation (4) does not apply to our case in a strict sense. However, the $R$ values at the incident angle of $22^{\circ}$ are nearly the same as those at the incident angle of $0^{\circ}, 35$ and the optical properties of the films are tentatively discussed on the basis of equation (4).

Part a in Figure 4 shows the transmission (a) and reflection spectra (b) of film ${ }_{\mathrm{ox}}$, and part b shows the spectral dependencies of $k$ (c) and $n$ (d) calculated by applying $T$ (spectrum a) and $R$ (spectrum b) to equations (1-3). Film $\mathrm{ox}_{\mathrm{x}}$ was prepared by stopping the potential sweep $\left(10 \mathrm{mV} \mathrm{s}^{-1}\right)$ at $1.3 \mathrm{~V}$ after the fifth potential sweep, and its thickness was $0.60 \mu \mathrm{m}$. The $n$ value of film ${ }_{\text {ox }}$ reached a minimum at $575 \mathrm{~nm}$ and a maximum at $850 \mathrm{~nm}$, which resulted in an anomalous dispersion in the absorption region. When the results of Figure $4 \mathrm{~b}$ are considered along with the relationship of equation (4), the $R$ values in the wavelength region of 500 to $\sim 700 \mathrm{~nm}$ are mainly dominated by $k$, and the $R$ values in the region above $750 \mathrm{~nm}$ are dominated by both $k$ and $n$. Similarly, the transmission (e) and reflection spectra (f) of film $\mathrm{red}_{\text {red }}$ are shown in part c, and the spectral dependencies of $k(\mathrm{~g})$ and $n(\mathrm{~h})$ of film $\mathrm{m}_{\text {red }}$ are demonstrated in part d. Film $\mathrm{m}_{\text {red }}$ was prepared by stopping the potential sweep at $-0.5 \mathrm{~V}$ after the fourth potential sweep, and its thickness was $0.43 \mu \mathrm{m}$. In this case, the $n$ value also reached a minimum at $400 \mathrm{~nm}$ and maximum at $540 \mathrm{~nm}$, and showed an anomalous dispersion in the absorption region. As observed from the similarity between the spectral shape of spectrum $f$ and spectrum $h$, the $R$ values are dominated by $n$ in the measured wavelength region. For film $\mathrm{cp}_{\mathrm{cp}}$, the transmission (i) and reflection spectra (j) were also recorded (Figure 4e), and the values of $k(\mathrm{k})$ and $n$ (1) were calculated as a function of the wavelength (Figure $4 \mathrm{f})$. This film $(0.56-\mu \mathrm{m}$ thick) was prepared by applying a potential of $1.2 \mathrm{~V}$ at $Q=0.065 \mathrm{C} \mathrm{cm}^{-2}$ in the electrolyte solution described in 'Experimental Procedure' section. On the basis of the similarity between the spectral shape of spectrum $j$ and spectrum 1 , the $R$ values are dominated by $n$. However, the $k$ (spectrum $\mathrm{k}$ ) and $n$ values (spectrum 1 ) of film $\mathrm{cp}_{\mathrm{cp}}$ are lower than the $k$ value of film $\mathrm{ox}_{\text {( }}$ sectrum $\mathrm{c}$ ) and the $n$ value of film $\mathrm{m}_{\mathrm{red}}$ (spectrum $\mathrm{h}$ ), respectively, which results in the reduced lustrous properties of film $\mathrm{cp}_{\mathrm{cp}}$. On the other hand, film ${ }^{\circ}(0.23-\mu \mathrm{m}$ thick $)$ is characterized by its higher $k$ (curve o in Figure 4h) and $n$ values (curve $\mathrm{p}$ in Figure $4 \mathrm{~h}$ ) compared with those of film $_{\mathrm{OX}}$, and this can account for the more lustrous properties of film ${ }^{\circ}$. A comparison among curves $\mathrm{c}, \mathrm{k}$ and o in Figure 4 suggests that the gold-like luster of the films is affected by $k$ to a greater extent and the degree of luster increases with an increase in $k$.

The development of the gold-like luster on film $_{\mathrm{ox}}$ was optically explained above. In the next step, the mechanism is considered on the basis of the film structures. It is generally accepted that polyalkylthiophenes are semicrystalline with crystalline domains surrounded by amorphous ones. ${ }^{36-43}$ The crystalline domains have an orthorhombic unit cell. For example, in the case of the cast film of poly(3-octylthiophene), the lattice parameters $a, b$ and $c$ were reported to be $2.07,0.38$ and $0.77 \mathrm{~nm}$, respectively. ${ }^{37}$ In addition, in the case of film ${ }^{\circ}$, we previously demonstrated that the crystal domains of the oligo(3-methoxythiophene) had a structure similar to that of poly(3-octylthiophene). ${ }^{12}$ Curve $\mathrm{c}$ in Figure 5a shows an XRD spectrum of film ${ }^{\circ} .^{12}$ The spectrum shows peaks at $2 \theta=7.84,15.84$ and $25.11^{\circ}$. The peaks at $2 \theta=7.84$ and 15.84 are the crystallographic (100) and (200) reflections, respectively, which indicates the layered structure of the oligomer (Figure $5 \mathrm{~b}$ ). The lamellar interlayer spacing was determined to be $1.13 \mathrm{~nm}$ from the dominant first-order reflection at $2 \theta=7.84^{\circ}$. The peak at $2 \theta=25.11^{\circ}$ corresponds to the (020) reflection associated with the $\pi-\pi$ stacking of the oligomer chains. The interchain distance between the $\pi$-stacking oxidized chains was calculated to be $0.35 \mathrm{~nm}$. The molecular modeling calculation (ChemBio3D Ultra 14, PerkinElmer) using the force field MM2 method on the oligomer demonstrated that the measured distance between the centers of the lamellae $(1.13 \mathrm{~nm})$ was substantially twice longer than the calculated distance between the center of the lamella and the methoxy proton furthest from the lamella $(0.566 \mathrm{~nm}$ including the van der Waals radii), and therefore, it was suggested that the methoxy chains of the lamellar layer are not necessarily interdigitated with those of the neighboring lamellar layers. Such crystallization would be caused by collaborative actions of $\pi-\pi$ stacking interaction, S.•.O interaction, ${ }^{44}$ and regioregularity effects. ${ }^{22,23}$ The dominance of the (100) peak in curve c indicates that the crystallites are preferentially oriented with the (100)-axis normal to the film and
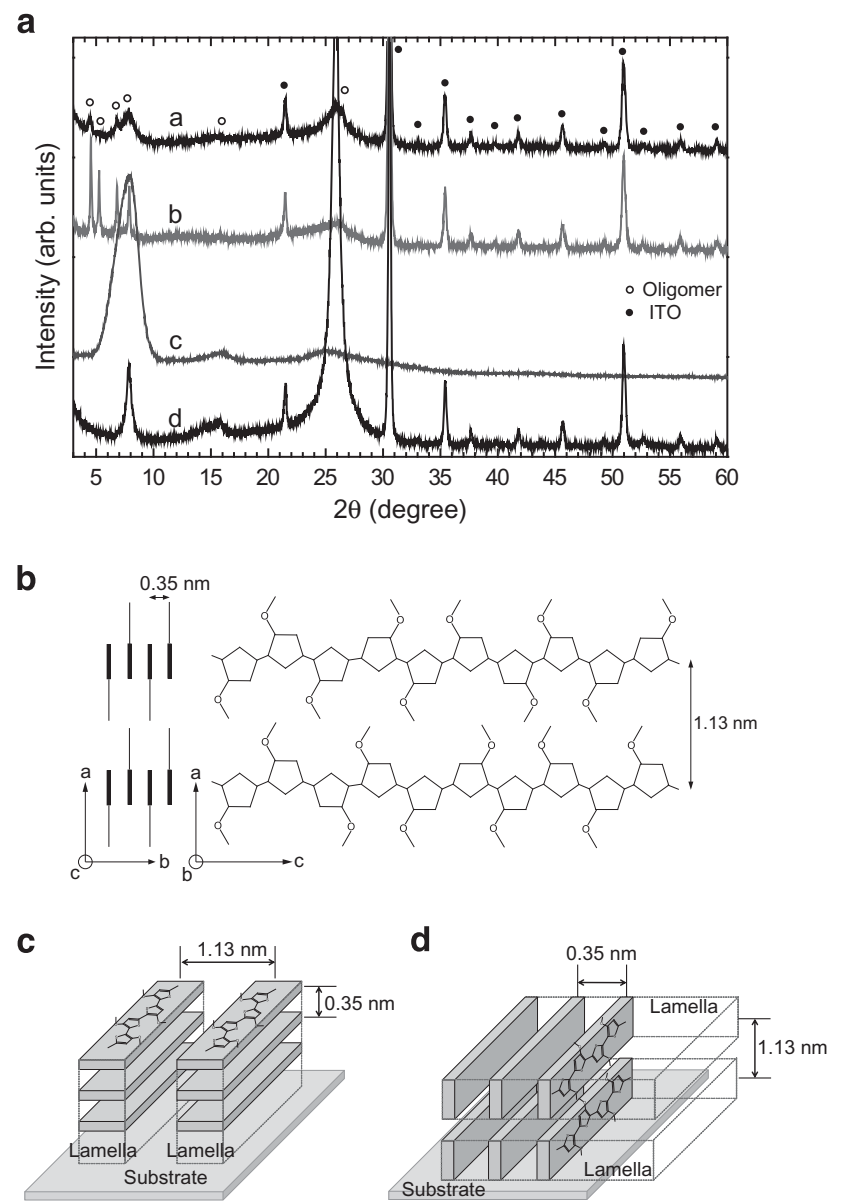

Figure 5 (a) X-ray diffraction (XRD) patterns of film ox (curve a, $4.0 \mu \mathrm{m}$ ), film $_{\text {red }}$ (curve b, 4- $\mu \mathrm{m}$ thick), film ${ }^{\circ}$ (curve c, 2.8- $\mu \mathrm{m}$ thick) and film $\mathrm{cp}_{\mathrm{cp}}$ (curve $\mathrm{d}, 4.3-\mu \mathrm{m}$ thick). Film $\mathrm{ox}_{\mathrm{x}}$, film $\mathrm{m}_{\text {red }}$ and film $\mathrm{mp}_{\mathrm{cp}}$ were deposited on the ITO, and film $^{\circ}$ was coated on a glass plate. (b) Schematic representation of the molecular arrangement of the oligomer. The parameters are taken from a. (c) The face-on lamellar structure. (d) The edge-on lamellar structure. A full color version of this figure is available at Polymer Journal online. 
Table 1 Electric conductivity of film ${ }_{\mathrm{ox}}$, film ${ }^{\circ}$ and film $\mathrm{cp}_{\mathrm{cp}}$ along the surface

\begin{tabular}{lcc}
\hline Film & $\sigma\left(\mathrm{S} \mathrm{cm}^{-1}\right)$ & Thickness $(\mu \mathrm{m})$ \\
\hline Film $_{\text {ox }}$ & $1.5 \times 10^{-4}$ & 2.0 \\
Film $^{\circ}$ & $3.6 \times 10^{-2}$ & 2.2 \\
Film $_{\mathrm{cp}}$ & $2.4 \times 10^{-5}$ & 1.8 \\
\hline
\end{tabular}

the (020)-axis parallel to the film. On the other hand, the dominance

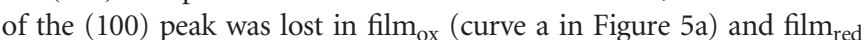
(curve $b$ in Figure 5a), suggesting that the microcrystalline lamella layer structure does not have a preferential orientation with respect to the substrate. Film $\mathrm{ox}_{\mathrm{x}}$ and film $\mathrm{m}_{\mathrm{red}}$ in this figure were prepared by stopping the potential sweep $\left(10 \mathrm{mV} \mathrm{s}^{-1}\right)$ at $1.3 \mathrm{~V}$ after the twentyfirst potential sweep and by stopping the potential sweep at $-0.5 \mathrm{~V}$ after the twentieth potential sweep, respectively. Their thickness was $4 \mu \mathrm{m}$. In addition, a narrowing of the (100) peak width occurred upon dedoping. This indicates an increase in the crystal size perpendicular to the substrate. Moreover, the (100) and (020) peak areas of film $\mathrm{ox}_{\mathrm{ox}}$ are larger than those of film $m_{\text {red, }}$ which shows that the content of the oligomer crystal is decreased by the dedoping of the film. Although the mechanism of the decrease in the ordering as a result of the dedoping is not clarified, it may be induced by the action of the dopant anion, ${ }^{36}$ $\mathrm{ClO}_{4}{ }^{-}$. In addition to the two lattice planes mentioned above, curve a contains peaks at $2 \theta=4.39$ and $6.75^{\circ}$, and sharp peaks at $4.39,5.20$ and $6.75^{\circ}$ were observed in curve b. If we assume that these peaks are attributed to a second polymorph, we may speculate that the dedoping treatment causes a conversion of the polymorph above to the second polymorph with a greater interlayer spacing and larger crystallite size. Further experiments are underway to elucidate the effect of doping and dedoping on the film structure.

Curve $d$ in Figure $5 \mathrm{a}$ shows the XRD pattern of film $\mathrm{cp}_{\mathrm{cp}}(4.3-\mu \mathrm{m}$ thick) prepared at $1.2 \mathrm{~V}$ by passing electricity, $Q=1.0 \mathrm{C} \mathrm{cm}^{-2}$. It exhibited peaks at $2 \theta=7.90,15.94$ and $25.90^{\circ}$. The area of the $(020)$ peak $\left(2 \theta=25.90^{\circ}\right)$ is considerably larger than that of film $\mathrm{ox}_{\mathrm{ox}}$ and the dominance of the (020) peak indicates that the crystallites are preferentially oriented with the (100)-axis parallel to the film and the (020)-axis normal to the film. In addition, the (100) and (020) peak widths of film $\mathrm{cp}_{\mathrm{cp}}$ are narrower than those of film $\mathrm{ox}_{\mathrm{ox}}$. These results indicate that the size of crystallites perpendicular to the substrate in film $_{\mathrm{cp}}$ is larger than that in film $\mathrm{ox}_{\mathrm{ox}}$ and the lamella preferentially adopts an orientation normal to the substrate (Figure $5 c$, face-on orientation), in contrast to the case in which the lamella preferentially has an orientation parallel to the substrate in film ${ }^{\circ}$ (Figure $5 \mathrm{~d}$, edge-on orientation). These two orientations coexist with each other in film ${ }_{\mathrm{Ox}}$ at almost the same ratio due to the fact that the (100) peak area is nearly the same as the (020) peak area. In a strict sense, these two orientations may be embedded into a disordered matrix, which is not depicted in Figures $5 \mathrm{c}$ and $5 \mathrm{~d}$ to avoid complications.

On the basis of the above experimental findings, the orientations of the lamella in the films are most likely associated with the gold-like lustrous characteristics. When considered along with the results in Figure 4, the $\alpha$ values of the films in the wavelength region above $\sim 500 \mathrm{~nm}$ should be higher when the incident light beam is parallel to the (100)-axis (or normal to the lamellar surface) than when it is parallel to the (020)-axis (or parallel to the lamellar surface). The higher values of $\alpha$ lead to higher values of $k$ (equation (3)), and in turn, lead to the higher gold-like luster. Therefore, the higher the ratio of the amount of edge-on lamellar structures to the face-on structures, the higher the gold-like luster. The increasing order of the amount ratio of the edge-on lamella, film $\mathrm{cp}_{\mathrm{cp}}<$ film $_{\mathrm{ox}}<$ film $^{\circ}$, is consistent with the order of the extent to which the films show a gold-like luster.

Table 1 shows the electric conductivities of film ${ }_{\mathrm{ox}}\left(\sigma_{\mathrm{Ox}}\right), \operatorname{film}^{\circ}\left(\sigma^{\circ}\right)$ and film $\mathrm{c}_{\mathrm{cp}}\left(\sigma_{\mathrm{cp}}\right)$. For the measurements of the electric conductivity by the four-point-probe method, a current is made to flow through the outer pair of probes, and a voltage drop is measured across the inner pair of probes. Thus, the obtained values describe the in-plane conductivity of the films. ${ }^{45-47}$ The value of $\sigma^{\circ}\left(3.6 \times 10^{-2} \mathrm{~S} \mathrm{~cm}^{-1}\right)$ is much higher than that of $\sigma_{\mathrm{cp}}\left(2.4 \times 10^{-5} \mathrm{~S} \mathrm{~cm}-1\right)$, and the anisotropy of the electronic conductivity, $\sigma^{\circ} / \sigma_{\mathrm{cp}}$, is $1.5 \times 10^{3}$. This result indicates that the edge-on lamellar orientation is more favorable for carrier hopping than the face-on lamellar orientation, which is consistent with the carrier mobility being limited by the $\pi-\pi$ interchain transport rather than the intrachain transport. ${ }^{48-50}$ In support of this finding, the value of $\sigma_{\mathrm{ox}}$ was between those of $\sigma^{\circ}$ and $\sigma_{\mathrm{cp}}$, as the amount ratio of the edge-on lamella to the entire lamellar structures in film $\mathrm{ox}_{\mathrm{ox}}$ is between the ratios in film ${ }^{\circ}$ and film $\mathrm{cp}_{\text {. }}$

\section{Mechanistic consideration of gold-like luster [II]}

As described in the previous section, the development of the gold-like luster of film $_{\mathrm{ox}}$ is significantly affected by the electrochemical techniques used. The formation of a lower lustrous film $\left(\right.$ film $\left._{\mathrm{cp}}\right)$ by the controlled-potential electrolysis technique suggests that the luster is not simply caused by the oligomer formation in the vicinity of an electrode and the subsequent deposition of the oligomer. ${ }^{51}$ In this case, the lamella preferentially adopts a face-on orientation, as described above. On the other hand, lustrous film formation by the potential-sweep technique suggests that the luster is caused by the structural changes that accompany the repetition of the dopingdedoping treatment. In Figure $5 \mathrm{a}$, the $(020)$ peak area of film $\mathrm{cp}_{\mathrm{cp}}$ is considerably larger than that of film $\mathrm{Ox}_{\mathrm{OX}}$, although their (100) peak areas are nearly the same. This result allows us to assume that the face-on lamella crystallite is preferentially destroyed over the edge-on lamella by the potential-sweep treatment. The preferential destruction of the face-on lamella increases the amount ratio of the edge-on to face-on lamellar structures, which results in the development of the gold-like luster. This consideration motivated us to carry out the preparation and subsequent potential-sweep treatment of film $\mathrm{m}_{\mathrm{cp}}$. The same film $\mathrm{cp}$ sample used in curve $d$ in Figure 3 was immersed in the mixed solvent of water/1-butanol (96:4 vol. ratio) containing $0.1 \mathrm{M}$ SDS and $0.1 \mathrm{M}$ $\mathrm{LiClO}_{4}$, and the potential-sweep treatment was carried out in the range of $-0.5 \mathrm{~V}$ to $1.3 \mathrm{~V}$ at a sweep rate of $10 \mathrm{mVs}^{-1}$. After the completion of the eleventh potential sweep, the sweep was stopped at 1.3 V. Part A in Figure 6 shows the reflection spectrum of the resulting film (abbreviated as film $\mathrm{pst}_{\mathrm{s}}$, curve a) and that of the as-grown film (curve b, reproduced from curve $d$ in Figure 3). Although there was little difference in appearance between the two films, the reflectance of the resulting film was a little larger than the reflectance of the asgrown film above the wavelength of $650 \mathrm{~nm}$, and the threshold wavelength at which the reflectance starts to rise shifted to longer wavelengths. This spectral change led us to measure the XRD pattern of the resulting film. Part B in Figure 6 shows the XRD pattern of film $\mathrm{pst}_{\text {(curve }}$ ) and that of film $\mathrm{m}_{\mathrm{cp}}$ (curve $\mathrm{d}$, reproduced from curve $\mathrm{d}$ in Figure $5 \mathrm{a}$ ). Although the signal intensities of film $\mathrm{m}_{\mathrm{pst}}$ at $2 \theta=7.90$ and $25.90^{\circ}$ are lower than those of film $\mathrm{cp}_{\mathrm{cp}}$ due to the smaller film thickness of the former, the signal intensity ratio is nearly the same. This result demonstrates that the destruction of the face-on lamella occurs when the potential-sweep treatment is carried out during the growth of the film but not when the treatment is performed after the film preparation. More unexpectedly, a new sharp peak appeared at $8.80^{\circ}$ in film $\mathrm{pst}_{\mathrm{p}}$, which indicates the formation of a new polymorph by the 

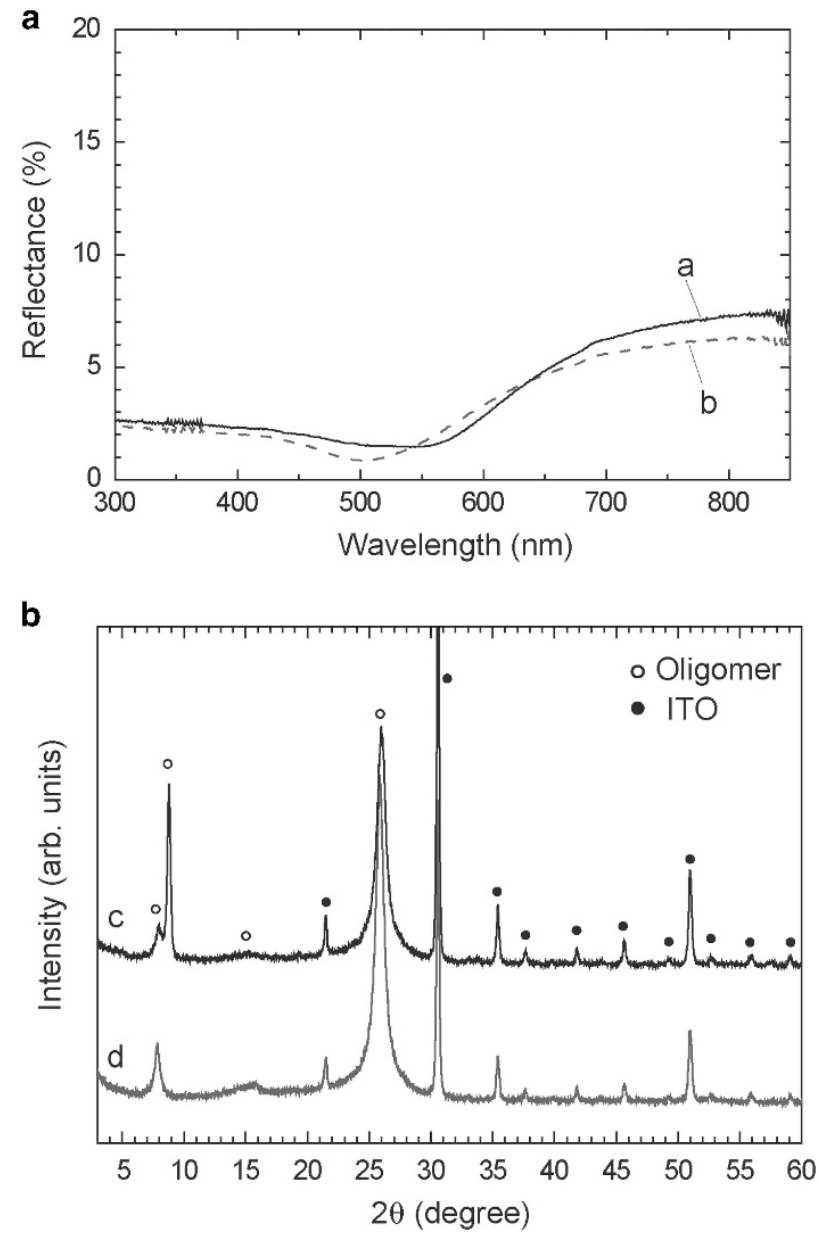

Figure 6 (a) Reflection spectra of film $\mathrm{m}_{\mathrm{pst}}\left(\mathrm{a}, 1.8-\mu \mathrm{m}\right.$ thick) and film $\mathrm{m}_{\mathrm{cp}}$ (b, 1.8- $\mu \mathrm{m}$ thick). (b) X-ray diffraction patterns of filmpst (a, 1.8- $\mu \mathrm{m}$ thick) and film $m_{c p}(b, 4-\mu m$ thick). A full color version of this figure is available at Polymer Journal online.

potential-sweep posttreatment of film $\mathrm{c}_{\mathrm{cp}}$ and suggests that this formation is associated with the spectral change in Figure 6a. We will thoroughly investigate this intriguing subject in the next step of our study.

The development of the gold-like luster depended on the range of the potential sweep, the sweep rate, and the number of potential sweeps. In the voltammograms shown in Figure 1b, a lower gold-like luster was observed when the low limit of the potential sweep was set to potentials more positive than $0 \mathrm{~V}$. Considering that full dedoping is completed at approximately $-0.5 \mathrm{~V}$, it is suggested that the full dedoping-induced drastic structural destruction of the face-on lamella is required for the development of the luster. However, even in the wide potential range of $-0.5 \mathrm{~V}$ to $1.3 \mathrm{~V}$, a lower gold-like lustrous feature was observed when the sweep rate was increased to 50,100 and $200 \mathrm{mV} \mathrm{s}^{-1}$, whereas the number of potential sweeps was maintained. When the potential range and the number of potential sweeps are the same, the total amount of electricity decreases with an increasing sweep rate, and hence, the film thickness decreases. The preliminary studies revealed that the film developed a gold-like luster when the film thickness exceeded $\sim 0.5 \mu \mathrm{m}$. This result led us to conclude that the number of potential sweeps has to be increased along with the potential sweep rate in such a way that the film thickness exceeds $\sim 0.5 \mu \mathrm{m}$. The absorption coefficient of film $\mathrm{ox}_{\mathrm{ox}}$ with a thickness below
$0.5 \mu \mathrm{m}$ was determined to be $1.1 \times 10^{5} \mathrm{~cm}^{-1}$ at $\lambda_{\max }=608 \mathrm{~nm}$, which gave a transmittance of $0.4 \%$. This shows that the lustrous feature becomes evident when the film has a high-shielding power. The effects of the potential-sweep range, the sweep rate, and the number of potential sweeps are now under investigation, and the details will be reported in a separate study.

In a metal-like coating industry, metal effect pigments, ${ }^{14}$ such as the flakes of aluminum, copper, copper-zinc alloys, zinc and so on, have found applications in automotive coatings, roof coatings, printing inks, cosmetics and plastic materials for protective and decorative functions. ${ }^{52}$ Such metal effect pigments are dispersed in a polymer binder solution containing colorants, and lustrous coatings are obtained by applying the dispersion. The size of the flake varies from a few micrometers to tens of micrometers, and its thickness is below $1 \mu \mathrm{m}$. The flakes need to lie parallel to a substrate; otherwise, a portion of light tends to be scattered, and the visual effect is sparkling rather than uniformly reflective. Thus, some additives are used so that a parallel orientation of the flakes may be achieved. Another disadvantage of metal effect pigments in connection with the size and specific gravity is sedimentation in the coating formulations. The role of the lamella formed by oligo(3-methoxythiophene) is the same as that of the metal flakes, however, the lamella are spontaneously aligned parallel to the substrate depending on the film-forming method used and are free from sedimentation. The size of the lamellar crystallite perpendicular to the substrate was estimated to be $3.5 \mathrm{~nm}$ from the half-value width of the (100) peak of film ${ }^{\circ}$ (curve $\mathrm{c}$ in Figure 5a) using Scherrer's formula. Similarly, the size of the lamellar crystallite perpendicular to the substrate was calculated to be $10.9 \mathrm{~nm}$ from the half-value width of the (020) peak of film $\mathrm{cp}_{\mathrm{cp}}$ (curve $d$ in Figure 5a). These calculation results provide a rough estimation that the size of the lamellar crystallite in the films is approximately several to $10 \mathrm{~nm}$. This size is $\sim 1 / 1000$ the size of the metal flakes. Although a clear-cut explanation for the development of the gold-like luster will require further research, it is possible to assume that a polycrystal composed of the nanosized lamellar crystallites would act as a light reflector.

\section{CONFLICT OF INTEREST}

The authors declare no conflict of interest.

\section{ACKNOWLEDGEMENTS}

This work was financially supported by the Ogasawara Foundation for the Promotion of Science \& Engineering. We would like to thank the Center for Analytical Instrumentation of Chiba University and Prof Shigeru Takahara for the measurements of reflection spectra and GPC analyses.

1 Ogura, K., Zhao, R., Yanai, H., Maeda, K., Tozawa, R., Matsumoto, S. \& Akazome, M. Facile formation of stable crystals with gold-like metallic luster from organic molecules: 1-aryl-2-(2-thienyl)-5-[5-(tricyanoethenyl)-2-thienyl]pyrroles. Bull. Chem. Soc. Jpn 75, 2359-2370 (2002).

2 Zhao, R., Akazome, M., Matsumoto, S. \& Ogura, K. Novel organic crystals with red-violet metallic luster: 1-aryl-2-(2-thienyl)-5-[5-(tricyanoethenyl)-2-thienyl]pyrrole derivatives bearing a heteroatom combined methyl substituent. Tetrahedron 2, 10225-10231 (2002).

3 Zhao, R., Matsumoto, S., M. Akazome, M. \& Ogura, K. Supramolecular architecture of metal-lustrous inclusion crystals based on aromatic $\mathrm{CH}-\pi$ interaction: versatile inclusion of 1-(p-ethoxyphenyl)-2-(2-thienyl)-5-[5-(tricyanoethenyl)-2-thienyl]pyrrole host with various electron-rich aromatic guest molecules. Tetrahedron 58, 10233-10241 (2002).

4 Ogura, K., Zhao, R., Jiang, M., Akazome, M., Matsumoto, S. \& Yamaguchi, K. Easy formation of gold-like lustrous crystals with a high melting point from 1-aryl-2,5-bis[5(tricyanoethenyl)-2-thienyl]pyrroles. Tetrahedron Lett. 44, 3595-3598 (2003).

5 Ogura, K., Zhao, R., Mizuoka, T., Akazome, M. \& Matsumoto, S. Formation of gold-like metal-lustrous inclusion crystals from 1-phenyl-2,5-bis[5-(tricyanoethenyl)-2-thienyl] 
pyrrole host and an electron-donating aromatic guest. Org. Biomol. Chem. 1, 3845-3850 (2003).

6 Ogura, K., Ooshima, K., Akazome, M. \& Matsumoto, S. Formation of metal-lustrous organic crystals from 2-aryl-1-(4-methoxyphenyl)-5-(5-tricyanoethenyl-2-thienyl)pyrroles. Tetrahedron 62, 2484-2491 (2006).

7 Matsumoto, A., Kawaharazuka, M., Takahashi, Y., Yoshino, N., Kawai, T. \& Kondo, Y. Gold-colored organic crystals formed from an azobenzene derivative. J. Oleo Sci 59, 151-156 (2010)

8 Kondo, Y., Matsumoto, A., Fukuyasu, K., Nakajima, K. \& Takahashi, Y. Gold-colored organic crystals of an azobenzene derivative. Langmuir 30, 4422-4426 (2014).

9 Kukino, M., Kuwabara, J., Matsuishi, K., Fukuda, T. \& Kanbara, T. Synthesis and metal-like luster of novel polyaniline analogs containing azobenzene unit. Chem. Lett. 39, 1248-1250 (2010).

10 Yamada, H., Kukino, M., Wang, Z.-A., Miyabara, R., Fujimoto, N., Kuwabara, J., Matsuishi, K. \& Kanbara, T. Preparation and characterization of green reflective films of polyaniline analogs containing azobenzene units. J. Appl. Polym. Sci. 132, 41275 (2015)

11 Goto, H. Crystal-liquid crystal ordered double layer electroactive polymer prepared with phase transition sequential polymerization, showing metallic electrochromism-bronze, silver, and gold. J. Polym. Sci. Pol. Chem. 51, 3097-3102 (2013).

12 Tagawa, R., Masu, H., Itoh, T. \& Hoshino, K. Solution-cast self-assembled films of perchlorate doped oligo(3-methoxythiophene) showing a gold-like luster. RSC Adv. 4, 24053-24058 (2014).

13 Smith, G. B., Gentle, A., Swift, P., Earp, A. \& Mronga, N. Coloured paints based on coated flakes of metal as the pigment, for enhanced solar reflectance and cooler interiors: description and theory. Sol. Energy Mater. Sol. Cells 79, 163-177 (2003).

14 Maile, F. J., Pfaff, G. \& Reynders, P. Effect pigments-past, present and future. Prog. Org. Coat. 54, 150-163 (2005)

15 Fall, M., Aaron, J.-J., Sakmeche, N., Dieng, M. M., Jouini, M., Aeiyach, S., Lacroix, J. C. \& Lacaze, P. C. Electrochemical and spectroscopic properties of poly(3-methoxythiophene) electrosynthesized in an aqueous micellar medium. Synth. Met. 93, 175-179 (1998).

16 Gningue-Sall, D., Fall, M., Dieng, M. M., Aaron, J.-J. \& Lacaze, P. C. Electrosynthesis and characterization of poly(3-methoxythiophene).polybithiophene composite films prepared in micellar media on Pt and Fe substrates. Phys. Chem. Chem. Phys. 1, 1731-1734 (1999).

17 Fall, M., Dieng, M. M., Aaron, J.-J., Aeiyach, S. \& Lacaze, P. C. Role of surfactants in the electrosynthesis and the electrochemical and spectroscopic characteristics of poly (3-methoxythiophene) films in aqueous micellar media. Synth. Met. 118 149-155 (2001)

18 Fall, M., Diagne, A. A., Dieng, M. M., Deflorian, F., Rossi, S., Bonora, P. L., Della Volpe, C. \& Aaron, J.-J. Electrochemical impedance spectroscopy of poly(3-methoxythiophene) thin films in aqueous $\mathrm{LiClO}_{4}$ solutions. Synth. Met. 155, 569-575 (2005).

19 Supplementary information in Kim, Y.-W., Tokuda, T., Yagishita, F., Masu, H., Kubo, M., Murashiro, K. \& Hoshino, K. Preparation of transparent conducting films with fillers of mixed-valence bicarbazyl nano/microtubes and wires. Chem. Lett. 43, 89-91 (2014).

20 Chang, A.-C., Blankespoor, R. L. \& Miller, L. L. Characterization and spectroelec trochemical studies of soluble polymerized 3-metoxythiphene. J. Electroanal. Chem. 236, 239-252 (1987).

21 Dong, B., Xu, J., Zheng, L. \& Hou, J. Electrodeposition of conductive poly(3methoxythiophene) in ionic liquid microemulsions. J. Electroanal. Chem. 628 60-66 (2009).

22 Sato, M. \& Morii, H. Nuclear magnetic resonance studies on electrochemically prepared poly(3-dodecylthiophene). Macromolecules 25, 4364-4372 (1992).

23 Botta, C. \& Stein, P. C. Spectroscopic analysis of structural defects in poly(3 decylthiophene)s: Influence of the polymerization method. J. Phys. Chem. 99, 3331-3337 (1995).

24 Zakaria, M. R., Abd-Aziz, S., Ariffin, H., Rahman, N. A. A., Yee, P. L. \& Hassan, M. A. Comamonas sp. EB172 isolated from digester treatingpalm oil mill effluent as potential polyhydroxyalkanoate (PHA) producer. Afr. J. Biotechnol. 7, 4118-4121 (2008).

25 Kerwin, S. M. Computer software reviews. J. Am. Chem. Soc. 132, 2466-2467 (2010)

26 Gottlieb, H. E. Kotlyar, V. \& Nudelman, A. NMR chemical shifts of common laboratory solvents as trace impurities. J. Org. Chem. 62, 7512-7515 (1997).

27 Yamaji, T., Saito, T., Hayamizu, K., Yanagisawa, M. \& Yamamoto, O. Spectral Database for Organic Compounds, National Institute of Advanced Industrial Science and Technology (AIST), Japan. Available from: http://sdbs.db.aist.go.jp/sdbs/cgi-bin/direct_frame_top.cgi. Accessed on August 2016.

28 Tanaka, S., Sato, M. \& Kaeriyama, K. Electrochemical polymerization of thiophenes containing a methoxy group. Polym. Commun. 26, 303-306 (1985).

29 Tanaka, S., Sato, M. \& Kaeriyama, K. Electrochemical preparation and properties of poly(3-methoxy-2,5-thiophenediyl) and poly(3-methylthio-2,5-thiophenediyl). Synth. Met. 25, 277-288 (1988)
30 Cattarin, S., Mengoli, G., Musiani, M. M. \& Schreck, B. Synthesis and properties of film electrodes from $\mathrm{N}$-substituted carbazoles in acid medium. J. Electroanal. Chem. 246 87-100 (1988).

31 Barr, G. E., Sayre, C. N., Connor, D. M. \& Collard, D. M. Polymerization of hydrophobic 3-alkylpyrroles from aqueous solutions of sodium dodecyl sulfate. Langmuir $\mathbf{1 2}$, 1395-1398 (1996).

32 Fall, M., Assogba, L., Aaron, J.-J. \& Dieng, M. M. Revisiting the electropolymerization of 3,4-dimethoxythiophene in organic and micellar media. Synth. Met. 123 , 365-372 (2001).

33 Farag, A. A. M. \& Fadel, M. Optical absorption and dispersion analysis of nanocrystalline perylene-3,4,9,10-tetracarboxylic-3,4,9,10-dianhydride film prepared by dipcoating and its optoelectronic application. Opt. Laser Technol. 45, 356-363 (2013).

34 El-Nahhas, M. M., Abdel-Khalek, H. \& Salem, E. Structural and optical properties of nanocrystalline 3,4,9,10-perylene-tetracarboxylic-diimide thin film. Adv. Condens. Matter Phys 2012, 698934 (2012).

35 Merano, M., Aiello, A., 't Hooft, G. W., van Exter, M. P., Eliel, E. R. \& Woerdman, J. P. Observation of Goos-Hänchen shifts in metallic reflection. Opt. Express 14, 15928-15934 (2007).

36 Winokur, M. J., Wamsley, P., Moulton, J., Smith, P. \& Heeger, A. J. Structural evolution in iodine-doped poly(3-alkylthiophenes). Macromolecules 24, 3812-3815 (1991).

37 Prosa, T. J., Winokur, M. J., Moulton, J., Smith, P. \& Heeger, A. J. X-ray structura studies of poly(3-alkylthiophenes): An example of an inverse comb. Macromolecules 25, 4364-4372 (1992).

38 McCullough, R. D., Tristram-Nagle, S., Williams, S. P., Lowe, R. D. \& Jayaraman, M Self-orienting head-to-tail poly(3-alkylthiophenes): new insights on structure-property relationships in conducting polymers. J. Am. Chem. Soc. 115, 4910-4911 (1993).

39 Aasmundtveit, K. E., Samuelsen, E. J., Guldstein, M., Steinsland, C., Flornes, O., Fagermo, C., Seeberg, T. M., Pettersson, L. A. A., Inganäs, O., Feidenhans'l, R. \& Ferrer, S. Structural anisotropy of poly(alkylthiophene) films. Macromolecules $\mathbf{3 3}$, 3120-3127 (2000).

40 Visy, C., Bencsik, G., Németh, Z. \& Vértes, A. Synthesis and characterization of chemically and electrochemically prepared conducting polymer/iron oxalate composites. Electrochim. Acta 53, 3942-3947 (2008).

41 Jose Abad, J., Pérez-García, B., Urbina, A., Colchero, J. \& Palacios-Lidón, E. Layered self-organized structures on poly(3-octylthiophene) thin films studied by scanning probe microscopy. Eur. Poly. J. 44, 2506-2515 (2008)

42 Abad, J., Espinosa, N., Ferrer, P., García-Valverde, R., Miguel, C., Padilla, J., Alcolea, A., Castro, G. R., Colchero, J. \& Urbina, A. Molecular structure of poly(3-alkylthiophenes) investigated by calorimetry and grazing incidence X-ray scattering. Sol. Energy Mater. Sol. Cells 97, 109-118 (2012).

43 Qu, Y., Li, L., Lu, G., Zhou, X., Su, Q., Xu, W., Li, S., Jidong Zhang, J. \& Yang, X. A novel melting behavior of poly(3-alkylthiophene) cocrystals: premelting and recrystallization of component polymers. Polym. Chem. 3, 3301-3307 (2012).

44 Nagao, Y., Hirata, T., Goto, S., Sano, S., Kakehi, A., lizuka, K. \& Shiro, M. Intramolecular nonbonded S...O interaction recognized in (acylimino)thiadiazoline derivatives as angiotensin $\mathrm{II}$ receptor antagonists and related compounds. J. Am. Chem. Soc. 120, 3104-3110 (1998).

45 Watanabe, A., Murakami, S., Mori, K. \& Kashiwabara, Y. Electronic properties of polypyrrole/n-Si heterojunctions and polypyrrole/metal contacts. Macromolecules 22 , 4231-4235 (1989).

46 Hasegawa, S. \& Grey, F. Electronic transport at semiconductor surfaces-from pointcontact transistor to micro-four-point probes. Surf. Sci. 500, 84-104 (2002).

47 Hulvat, J. F. \& Stupp, S. I. Anisotropic properties of conducting polymers prepared by liquid crystal templating. Adv. Mater. 16, 589-592 (2004).

48 Bao, Z., Dodabalapur, A. \& Lovinger, A. J. Soluble and processable regioregular poly(3hexylthiophene) for thin film field-effect transistor applications with high mobility. Appl. Phys. Lett. 69, 4108-4110 (1996).

49 Sirringhaus, H., Brown, P. J., Friend, R. H., Nielsen, M. M., Bechgaard, K. Langeveld-Voss, B. M. W., Spiering, A. J. H., Janssen, R. A. J., Meijer, E. W., Herwig, P. \& de Leeuw, D. M. Two-dimensional charge transport in self-organized, high-mobility conjugated polymers. Nature 401, 685-688 (1999).

50 Liu, C., Oshima, K., Shimomura, M. \& Miyauchi, S. Anisotropic conductivitytemperature characteristic of solution-cast poly(3-hexylthiophene) films. Synth. Met. 156, 1362-1367 (2006).

51 John, R. \& Wallace, G. G. The use of microelectrodes to probe the electropolymerization mechanism of heterocyclic conducting polymers. J. Electroanal. Chem. 306, 157-167 (1991).

52 Liu, H., Ye, H. \& Zhang, Y. Preparation and characterization of PMMA/flaky aluminium composite particle in the presence of MPS. Colloids Surf. A: Physicochem. Eng. Aspects 315, 1-6 (2008).

Supplementary Information accompanies the paper on Polymer Journal website (http://www.nature.com/pj) 